\title{
Hysterectomy for benign conditions in a tertiary care centre: a clinical audit
}

\author{
K. Hymavathi*, P. V. Sreeleena Madhuri, Maddipudi. Brahmini, Sakthi Madhubala
}

Department of Obstetrics and Gynaecology Narayana Medical College and Hospital, Nellore, Andhra Pradesh, India

Received: 15 December 2020

Accepted: 19 January 2021

\section{*Correspondence:}

Dr. K. Hymavathi,

E-mail: dr.hymakrreddy@gmail.com

Copyright: (c) the author(s), publisher and licensee Medip Academy. This is an open-access article distributed under the terms of the Creative Commons Attribution Non-Commercial License, which permits unrestricted non-commercial use, distribution, and reproduction in any medium, provided the original work is properly cited.

\begin{abstract}
Background: This clinical audit is to determine the indications, type, and outcome of hysterectomy performed for benign gynaecological conditions in two years and to identify the problem or issue (if any) in planning the hysterectomy for benign conditions.

Methods: The present study is a hospital-based prospective study conducted in the Department of Obstetrics and Gynaecology, Narayana Medical College and Hospital, a tertiary care centre, Nellore, AP. Six hundred women, who underwent the hysterectomy during the study period are recruited into this study after obtaining hospital ethical committee approval and informed consent. Among the total of 50,450 women attended our OPD for gynaecological complaints, 600 patients underwent the hysterectomy. Thus $9.6 \%$ of total gynaecological admissions ended up with the hysterectomy.

Results: The mean age group of the study is $49.07 \pm 8.0$ years. Majority of women belonged to low socio-economic status. Predominant age group underwent hysterectomy was 40-49 years. Majority (78.2\%; 469 cases) of hysterectomies were done in multiparous women. Chief complaints were menstrual irregularities. Abnormal uterine bleeding -leomyoma (AUB-L) (228 cases; 38\%) was the most common indication for hysterectomy. Most commonly done procedure was total abdominal hysterectomy TAH $(60.5 \% ; 363$ cases). 306 cases $(51 \%)$ had oophorectomy (beyond the age of 45 years).The various complications (hemorrhage, sepsis etc..) found to happen mainly in hysterectomies done through abdominal route. $95 \%$ of hysterectomised histopathological specimen's histopathology reports correlated with the pre-operative biopsy reports.

Conclusions: In proved benign conditions, women were counselled and encouraged for medical and conservative methods. Hysterectomies should be decided in those situations where the above measures fail and also where it was found to be the definitive management in the first instance. Woman's option has also to be considered in certain cases. The route of hysterectomy has to be decided case to case basis and choice of the attending clinician. Oophorectomy was decided in the premenopausal women depending on the condition of the ovaries witnessed at the time of surgery.
\end{abstract}

Keywords: Benign gynecological conditions, Haemorrhage, Hysterectomy, Oophorectomy

\section{INTRODUCTION}

Hysterectomy is defined as surgical removal of the uterus. $^{1}$ The most frequently performed major gynaecological operation over the world next to caesarean section is hysterectomy. ${ }^{2}$ In the industrialized world hysterectomy are high with an incidence of
$42 / 100,000$ in the UK, $143 / 100,000$ in the USA and $236 / 100,000$ in the Germany respectively. In India, it accounts for $6 \%$ of major surgeries. Over 1.2 million women globally, can expect to undergo this form of surgical procedure annually. One in five women will experience this surgical procedure at some point in their lives. ${ }^{3}$ Earlier, hysterectomies were associated with high 
morbidity and mortality mainly, from haemorrhage and infection. However, the use of potent antibiotics, improvement in blood banking services and safe anaesthetic techniques have reduced the morbidity and mortality associated with hysterectomy. It is done by two routes: (1) Abdominal (2) Vaginal and (3) Laparoscopic.

It has been a remarkable improvement in conservative management of uterine lesions still hysterectomy remains the most preferred modality of treatment. Most women have relief from their symptoms after hysterectomy with the associated high level of satisfaction with the procedure.

The most frequent indication for hysterectomy is uterine fibroid. The other indications include Adenomyosis, Endometriosis, pelvic organ prolapse, postmenopausal bleeding. This procedure can be done prophylactically against reproductive tract cancers especially in those with a strong family history such as breast cancer with BRCA1 or 2 mutations.

The current study is a clinical audit regarding hysterectomy for benign conditions in the department of obstetrics and gynaecology, Narayana medical college and hospital over two years (October 2017 to October 2019).

The indications are often overused in this field of nonmalignant hysterectomy, resulting in many unnecessary operations. Hence this study will bring the facts and figures about the clinical indications and final histopathological diagnosis and throw some conclusion on the justification of hysterectomy.

In contemporary clinical practice, enough information should be given to the patient regarding the reason for the treatment offered, the benefits and the risks of the treatment and the alternative options. This ideal has not been fulfilled satisfactorily for women undergoing a hysterectomy. The reason for this is that Gynaecologists, owing to limitations in their training, have not always been able to offer their patients a genuine choice of treatment options.

The aims of our study are to determine the indications, type, and outcome of hysterectomy performed for benign gynaecological conditions over a period of two years, to identify the problem or issue (if any) in planning the hysterectomy for benign conditions, to set the criteria and standards regarding the issue, to observe the practice, to compare performance with criteria and standards and to implement the change.

\section{METHODS}

\section{Data sources}

This is a prospective study done in the Department of Obstetrics and Gynaecology, Narayana Medical College and Hospital, Nellore for a period of 2 years. (October 2017 to October 2019).

\section{Source of the study}

All the women attending Gynaecology Outpatient Department, Narayana Medical College and Hospital.

Type of study: Prospective observational study.

Sample size: 600 cases who underwent hysterectomy.

\section{Inclusion criteria}

Pre and post menopausal women with complaints of bleeding per vagina, chronic pelvic pain and mass per vagina with clinical, radiological and histopathological findings suggestive of benign pathological condition.

\section{Exclusion criteria}

Women with proved gynaecological malignancies. Women who refused to give consent.

\section{Patient analysis}

Institutional ethical committee of Narayana Medical College and Hospital, Nellore, Andhra Pradesh has approved the study with the following ethical considerations:

No bias when sample selection was done with respect to age, parity, socioeconomic status.

Written and informed consent was taken before their recruitment into the study.

The study group should not be exposed to any increased risk as a result of the study.

Confidentiality should be maintained.

All the women attending gynaecology OPD was subjected to detailed history, and examination. Patients with benign gynaecological symptoms and specific findings on examination were admitted for histopathological study and investigations. Most of patients with benign conditions were treated with medical and conservative methods. But for those women who need surgical management, not responding to medical or conservative methods, not willing for the conservative and medical methods or due to intraoperative complications during conservative surgeries hysterectomy was done. The histopathology report of the specimen was correlated with preoperative diagnosis for the justification of hysterectomies done in Narayana medical college and hospital. The hysterectomised women attended to OPD for follow-up were observed for complications due to surgery. 


\section{Methodology}

Demographic details like Name, Age, Address, Occupation, Socioeconomic status and presenting complaints of all the women attending gynaecology OPD was collected and detailed history regarding menstrual history, obstetric history, marital history, past medical history (Any complaints of hypertension, diabetes, Tuberculosis, venereal disease, any previous operative procedures, if so nature of surgery and anaesthesia, if any previous blood transfusion), family history (any genital or breast malignancy, among patient's sisters, mother, maternal aunts) was also taken. Detailed general and systemic examination was done. On abdominal examination any palpable mass, organomegaly, tenderness, ascites, position of umbilicus, any engorged veins and hernial sites were noted. Local examination of external genitalia, tests for incontinence, per speculum examination findings, status of vagina and cervix, descent of uterus and any discharge per vagina, position and mobility of uterus, forniceal status and recto vaginal examination were also done. Apart from the routine investigation's specific investigations like ultrasonography, pap smear, biopsy (cervical and endometrial) were done to arrive at the final diagnosis and to decide the line of management (medical/conservative methods/hysterectomy). Following the final diagnosis women were decided for hysterectomy were recruited in to the study after taking the informed consent. Post hysterectomy diagnosis was correlated with pre-operative diagnosis Hysterectomised women were followed up for a period of 6months. Parameters like indication, type of hysterectomy, intraoperative complications and histopathological reports, follow-up outcomes were analysed.

\section{Statistics analysis}

The data obtained from our study was analysed using SPSS software version 22.0 to generate graphs and tables.

\section{RESULTS}

A total of 50,450 women attended our outpatient department (OPD) with gynaecological complaints and 6,230 were admitted in the hospital for the symptoms like bleeding/spotting per vaginum, menstrual irregularities, mass per vaginum, mass per abdomen, pain abdomen, foul smelling WDPV, dyspareunia etc.. Out of which 2,850 patients were diagnosed to be having benign gynaecological conditions of which 1,890 patients were treated with medical management, 310 patients opted and treated with conservative procedures and 600 patients with surgical management (hysterectomy).

Thus $9.6 \%$ of total gynaecological admissions required hysterectomy. The entire information (pre and postoperative) of hysterectomised women was analysed.

\section{Socio-economic status}

In our study among 600 cases, 530 women were belong to low socio economic status and 70 women belong to middle class based on kuppuswamy classification.

\section{Age}

Among the total cases (600), $0.3 \%$ ( 2 cases) belongs to the age group 20-29years, $11.8 \%$ (71 cases) belongs to the age group $30-39$ years, $45.7 \%$ (274 cases) belongs to the age group $40-49$ years, $32.5 \%$ ( 195 cases) belongs to the age group 50-59 years, $9.0 \%$ (54 cases) belongs to the age group $60-69$ years and $0.7 \%$ ( 4 cases) belongs to the age group $>70$ years.

Mean age group of the study is $49.07 \pm 8.0$ years. Maximum number (274 cases) of hysterectomised women were found to be in the age group 40-49 years and the minimum number ( 2 cases) found to be between 20-29 years.

\section{Parity}

The total cases of the study are sub divided as $0.3 \%$ (2 cases) of nulliparous woman, $2.5 \%$ (15 cases) with para $1,78.2 \%$ (469 cases) with para 2 to para 3 and $19 \%$ (114 cases) with para 4 to para 7.

In this study, majority (78.2\%; 469 cases) of hysterectomies were done in women with 2 to 3 parity and the same was done in only 2 cases $(0.3 \%)$ of nulliparous women.

\section{Marital status}

Among the total cases who underwent hysterectomy, 0.3 $\%$ ( 2 cases) were unmarried, $92.5 \%$ (555 cases) were married.

\section{Chief complaints}

305 cases $(50.83 \%)$ with menstrual irregularities, 127 cases $(21.17 \%)$ with mass per vaginum, 92 cases (15.33\%) with bleeding /spotting per vaginum,60 cases (10\%) with Pain abdomen, foulsmelling WDPV, dyspareunia and 16 cases $(2.67 \%)$ with mass per abdomen. According to our study, maximum number of hysterectomies were done in women presenting with complaints of menstrual irregularities $(50.83 \%$; 305 cases) and the minimum with complaints of mass per abdomen $(2.67 \% ; 16$ cases).

\section{Indications of hysterectomy}

The indications for hysterectomy were found to be as follows: 306 cases $(51 \%)$ with AUB, 127 cases $(21.17 \%)$ with Uterine Prolapse, 92 cases $(15.33 \%)$ with PostMenopausal Bleeding, 60 cases (10\%) with Chronic PID, 15 cases $(2.5 \%)$ with Benign ovarian Tumours. Among the AUB $38 \%$ found to be $\operatorname{AUB}(\mathrm{L})$. Others being AUB(A), AUB(E), AUB(P). 


\section{Type of hysterectomy}

TAH was done in 363 cases $(60.5 \%), 127$ cases $(21.2 \%)$ with VH for uterine prolapse, 101 cases $(16.8 \%)$ with TLH, 7 cases $(1.2 \%)$ with NDVH, and 2 cases $(0.3 \%)$ with TLH->TAH.

\section{Complications of hysterectomy}

Out of 600 cases 538 went on uneventfully with no complications. The complications of the study population were distributed as follows: 30 cases $(5.0 \%)$ with Haemorrhage, 5 cases $(0.8 \%)$ with Bowel injury, 11 cases (1.8\%) with Bladder Injury, 12 cases (2\%) with Burst Abdomen, 1 case $(0.2 \%)$ each with Acute Renal Failure,
Vault Granuloma, Vesico Vaginal Fistula and Recto Vaginal Fistula. 538 cases $(89.7 \%)$ did not have any complications.

\section{Oopherectomy}

Among the total cases, $51 \%$ had Oopherectomy mostly in the postmenopausal group.

\section{Histopathological correlation of hysterectomised specimen with pre operative biopsy}

In our study, 95\% hysterectomized specimen's correlated with preoperative biopsy. Such correlation was not seen in the remaining $5 \%$ of the cases.

Table 1: Age versus type of hysterectomy.

\begin{tabular}{|c|c|c|c|c|c|c|c|}
\hline \multirow{2}{*}{$\begin{array}{l}\text { Age } \\
\text { (in years) }\end{array}$} & \multicolumn{7}{|c|}{ Surgical procedure } \\
\hline & TAH & TAH+BSO & VH & NDVH & TLH & TLH to TAH & Total \\
\hline \multirow{2}{*}{$20-29$} & 1 & 0 & 0 & 0 & 1 & 0 & 2 \\
\hline & $50.0 \%$ & $0.0 \%$ & $0.0 \%$ & $0.0 \%$ & $50.0 \%$ & $0.0 \%$ & $100.0 \%$ \\
\hline \multirow{2}{*}{ 30-39 } & 36 & 27 & 0 & 1 & 7 & 0 & 71 \\
\hline & $50.7 \%$ & $38.0 \%$ & $0.0 \%$ & $1.4 \%$ & $9.9 \%$ & $0.0 \%$ & $100.0 \%$ \\
\hline \multirow{2}{*}{$40-49$} & 143 & 47 & 3 & 6 & 74 & 1 & 274 \\
\hline & $52.2 \%$ & $17.2 \%$ & $1.1 \%$ & $2.2 \%$ & $27.0 \%$ & $0.4 \%$ & $100.0 \%$ \\
\hline \multirow{2}{*}{$50-59$} & 9 & 97 & 69 & 0 & 19 & 1 & 195 \\
\hline & $4.6 \%$ & $49.7 \%$ & $35.4 \%$ & $0.0 \%$ & $9.7 \%$ & $0.5 \%$ & $100.0 \%$ \\
\hline \multirow{2}{*}{$60-69$} & 1 & 2 & 51 & 0 & 0 & 0 & 54 \\
\hline & $1.9 \%$ & $3.7 \%$ & $94.4 \%$ & $0.0 \%$ & $0.0 \%$ & $0.0 \%$ & $100.0 \%$ \\
\hline \multirow{2}{*}{$>70$} & 0 & 0 & 4 & 0 & 0 & 0 & 4 \\
\hline & $0.0 \%$ & $0.0 \%$ & $100.0 \%$ & $0.0 \%$ & $0.0 \%$ & $0.0 \%$ & $100.0 \%$ \\
\hline \multirow{2}{*}{ Total } & 94 & 269 & 127 & 7 & 101 & 2 & 600 \\
\hline & $15.7 \%$ & $44.8 \%$ & $21.2 \%$ & $1.2 \%$ & $16.8 \%$ & $0.3 \%$ & $100.0 \%$ \\
\hline \multicolumn{8}{|c|}{ Chi-Square Tests } \\
\hline & Value & Df & P-Value & & & & \\
\hline $\begin{array}{l}\text { Pearson Chi- } \\
\text { Square }\end{array}$ & $384.943 \mathrm{a}$ & 25 & 0.0001 & & & & \\
\hline
\end{tabular}

Table 2: Clinical diagnosis versus type of surgical procedure.

\begin{tabular}{|c|c|c|c|c|c|c|c|}
\hline \multirow{2}{*}{$\begin{array}{l}\text { Clinical } \\
\text { diagnosis }\end{array}$} & \multicolumn{7}{|c|}{ Surgical procedure } \\
\hline & TAH & TAH+BSO & VH & NDVH & TLH & TLH to TAH & Total \\
\hline \multirow{2}{*}{$\mathbf{A U B}(\mathbf{L})$} & 7 & 142 & 0 & 2 & 76 & 1 & 228 \\
\hline & $3.1 \%$ & $62.3 \%$ & $0.0 \%$ & $0.9 \%$ & $33.3 \%$ & $0.4 \%$ & $100.0 \%$ \\
\hline \multirow{2}{*}{ Prolapse } & 0 & 0 & 127 & 0 & 0 & 0 & 127 \\
\hline & $0.0 \%$ & $0.0 \%$ & $100.0 \%$ & $0.0 \%$ & $0.0 \%$ & $0.0 \%$ & $100.0 \%$ \\
\hline \multirow{2}{*}{ PMB } & 0 & 90 & 0 & 0 & 2 & 0 & 92 \\
\hline & $0.0 \%$ & $97.8 \%$ & $0.0 \%$ & $0.0 \%$ & $2.2 \%$ & $0.0 \%$ & $100.0 \%$ \\
\hline \multirow{2}{*}{$\begin{array}{l}\text { Chronic } \\
\text { PID }\end{array}$} & 33 & 22 & 0 & 3 & 1 & 1 & 60 \\
\hline & $55.0 \%$ & $36.7 \%$ & $0.0 \%$ & $5.0 \%$ & $1.7 \%$ & $1.7 \%$ & $100.0 \%$ \\
\hline \multirow{2}{*}{$\operatorname{AUB}(\mathbf{A})$} & 54 & 1 & 0 & 2 & 0 & 0 & 57 \\
\hline & $94.7 \%$ & $1.8 \%$ & $0.0 \%$ & $3.5 \%$ & $0.0 \%$ & $0.0 \%$ & $100.0 \%$ \\
\hline \multirow{2}{*}{ AUB(E) } & 0 & 14 & 0 & 0 & 0 & 0 & 14 \\
\hline & $0.0 \%$ & $100.0 \%$ & $0.0 \%$ & $0.0 \%$ & $0.0 \%$ & $0.0 \%$ & $100.0 \%$ \\
\hline \multirow{2}{*}{$\operatorname{AUB}(\mathbf{P})$} & 0 & 0 & 0 & 0 & 7 & 0 & 7 \\
\hline & $0.0 \%$ & $0.0 \%$ & $0.0 \%$ & $0.0 \%$ & $100.0 \%$ & $0.0 \%$ & $100.0 \%$ \\
\hline
\end{tabular}

Continued. 


\begin{tabular}{|llllllll|}
\hline $\begin{array}{l}\text { Clinical } \\
\text { diagnosis }\end{array}$ & \multicolumn{2}{l}{ Surgical procedure } & & & & & \\
\cline { 2 - 7 } Ovarian & TAH & TAH+BSO & VH & NDVH & TLH & TLH to TAH & Total \\
\hline Cyst & 0 & 0 & 0 & 0 & 15 & 0 & 15 \\
\hline \multirow{2}{*}{ Total } & $0.0 \%$ & $0.0 \%$ & $0.0 \%$ & $0.0 \%$ & $100.0 \%$ & $0.0 \%$ & $100.0 \%$ \\
\hline
\end{tabular}

In our study, the most common age group underwent hysterectomy was 40-49 years, followed by age group 50-59 years. In 30-39 years, (71 patients in total), TAH without BSO was commonly done in patients $(50.7 \%)$, $\mathrm{TAH}+\mathrm{BSO}$ in 27 patients $(38 \%)$, TLH in 7 patients (9.9\%), NDVH in 1 patient $(1.4 \%)$ and no vaginal hysterectomies were done in this age group.
The above Table shows highest number of hysterectomies being performed in women with AUB(L). $\mathrm{TAH}+\mathrm{BSO}$ was done in 142 cases.

All the patients of uterine prolapse being in the post menopausal group underwent oophorectomy.

Table 3: Type of hysterectomy versus complications.

\begin{tabular}{|c|c|c|c|c|c|c|c|}
\hline \multirow{2}{*}{ Complications } & \multicolumn{7}{|c|}{ Surgical procedure } \\
\hline & TAH & TAH+BSO & VH & NDVH & TLH & TLH to TAH & Total \\
\hline \multirow{2}{*}{ No complications } & 94 & 214 & 124 & 7 & 99 & 0 & 538 \\
\hline & $17.5 \%$ & $39.8 \%$ & $23.0 \%$ & $1.3 \%$ & $18.4 \%$ & $0.0 \%$ & $100.0 \%$ \\
\hline \multirow{2}{*}{ Hemorrhage } & 0 & 21 & 9 & 0 & 0 & 0 & 30 \\
\hline & $0.0 \%$ & $69.3 \%$ & $29.7 \%$ & $0.0 \%$ & $0.0 \%$ & $0.0 \%$ & $100.0 \%$ \\
\hline \multirow{2}{*}{ Burst abdomen } & 0 & 11 & 0 & 0 & 1 & 1 & 13 \\
\hline & $0.0 \%$ & $84.6 \%$ & $0.0 \%$ & $0.0 \%$ & $7.7 \%$ & $7.7 \%$ & $100.0 \%$ \\
\hline \multirow{2}{*}{ Bladder injury } & 0 & 9 & 0 & 0 & 1 & 0 & 10 \\
\hline & $0.0 \%$ & $90.0 \%$ & $0.0 \%$ & $0.0 \%$ & $10.0 \%$ & $0.0 \%$ & $100.0 \%$ \\
\hline \multirow{2}{*}{ Bowel injury } & 0 & 5 & 0 & 0 & 0 & 0 & 5 \\
\hline & $0.0 \%$ & $100.0 \%$ & $0.0 \%$ & $0.0 \%$ & $0.0 \%$ & $0.0 \%$ & $100.0 \%$ \\
\hline \multirow{2}{*}{ Vault granuloma } & 0 & 0 & 1 & 0 & 0 & 0 & 1 \\
\hline & $0.0 \%$ & $0.0 \%$ & $100.0 \%$ & $0.0 \%$ & $0.0 \%$ & $0.0 \%$ & $100.0 \%$ \\
\hline \multirow[b]{2}{*}{ ARF } & 0 & 0 & 0 & 0 & 0 & 1 & 1 \\
\hline & $0.0 \%$ & $0.0 \%$ & $0.0 \%$ & $0.0 \%$ & $0.0 \%$ & $100.0 \%$ & $100.0 \%$ \\
\hline \multirow[b]{2}{*}{ VVF } & 0 & 1 & 0 & 0 & 0 & 0 & 1 \\
\hline & $0.0 \%$ & $100.0 \%$ & $0.0 \%$ & $0.0 \%$ & $0.0 \%$ & $0.0 \%$ & $100.0 \%$ \\
\hline \multirow[b]{2}{*}{ RVF } & 0 & 0 & 1 & 0 & 0 & 0 & 1 \\
\hline & $0.0 \%$ & $0.0 \%$ & $100.0 \%$ & $0.0 \%$ & $0.0 \%$ & $0.0 \%$ & $100.0 \%$ \\
\hline \multirow[b]{2}{*}{ Total } & 94 & 269 & 127 & 7 & 101 & 2 & 600 \\
\hline & $15.7 \%$ & $44.8 \%$ & $21.2 \%$ & $1.2 \%$ & $16.8 \%$ & $0.3 \%$ & $100.0 \%$ \\
\hline
\end{tabular}

Hysterectomy outcome was not complicated in 538 cases. The most common complication associated with hysterectomy was hemorrhage. Hemorrhagic complications were seen in around 30 cases- 21 of $\mathrm{TAH}+\mathrm{BSO}$ and 9 cases of $\mathrm{VH}$ for uterine prolapse. Primary hemorrhage was observed in mostly in cases of endometriosis and large long standing uterine prolapse.

\section{DISCUSSION}

In Narayana medical college and hospital (a teaching hospital), a total of 600 hysterectomies were performed over two years contributing to $9.6 \%$ of total gynaecological admissions.
According to the study conducted by Shridevi et al., women at 31-40 years of age group were $21(7.0 \%)$, at 41-50 years of age were $145(48.3 \%)$, at 51-60 years of age were $96(32.0 \%)$, age 61 and above were 38 $(12.6 \%) .{ }^{5}$ Our study results are consistent with the above study of hysterectomies done in the age groups of 41-50, $51-60,61$ and above years. Only the age of 31-40 years our results differed with above study $(11.8 \%$ versus $7 \%)$.

Amirika et al, reported higher incidence of hysterectomies among parous women and only 5\% of women were nulliparous, where as in our study $97.7 \%$ were multiparous and $0.3 \%$ were nulliparous women. ${ }^{6}$

Rao PMR, et al, reported that among the hysterectomised 
women maximum number $(54.9 \%)$ presented with complaints of menstrual irregularities next in order being mass per vaginum $(24 \%){ }^{8}$ Watt et al and Emil F Cava reported that maximum number of hysterectomies were done for menstrual irregularities, where as in our study the corresponding figures were $50.83 \%$ and $21.17 \%$ respectively. ${ }^{7}$

As per studies of Rekharao et al among the hysterectomies performed the commonest indication was AUB(L)-31\% and mass per vaginum. The present study also have near corresponding figures (38\% and $21.17 \%)$ respectively.

Aruna devi et al and Sucheta KL et al reported that most of their hysterectomy cases were TAH (64\% and 63\%) respectively, in our study $60.5 \%$ is the corresponding figure. The figures for TLH and $\mathrm{VH}$ were also consistent with the above studies (14\% and $22 \%$ versus $16.5 \%$ and $22.2 \%$ ) respectively. In our study $0.3 \%$ cases decided for TLH had to be converted to TAH due to severe endometriosis (dense adhesions causing unsatisfactory pneumoperitoneum and troublesome oozing).

When hysterectomy is performed only for benign reasons, 1-6 per 1000 women are reported to have short and long term morbidity. Rate of various complications with hysterectomy has been reported in the range from $0.5 \%$ to $43 \% .^{11}$

The various studies reported in the literature for hemorrhagic complications in hysterectomy cases ranging from $1.3-15 \%$, the present study figure is $(5 \%)$ nearer to the studies of Deeksha et al and Verma D et al $(3.8 \%$ and $3.9 \%)$ respectively. In the present study the hemorrhagic complications mainly happened in cases of severe endometriosis and long standing cases of large uterine prolapse. Wound gaping and sepsis complications in various studies are found to be ranging from 1.2-16\%, our study figure is $2 \%$. The incidence of bladder and bowel injuries ranging from $0.87-3.6 \%$. The other rare complications like vault granulomas etc. The literature incidence around $1.5 \%$, where as our's is $0.2 \%$. In the study of Rojora et al the mortality incidence was found to be $0.8 \%$ but in the present study mortality figure is zero.

There was a fall in the incidence of TAH with BSO from $31.4 \%$ in 2009 to $10.37 \%$ in 2014 . The decision of removing the ovaries should be made based on an assessment of risk and age In our study, among the total cases (600), 51\% (306) underwent oophorectomy which includes all postmenopausal women and women in the pre and perimenopausal age group, out of 347 cases, 47 were oopherectomised the causes being unhealthy ovaries and unilateral/bilateral tumors \& some patients had unilateral oophorectomy previously prior to hysterectomy because of ovarian problems.

In the study of Sivapragasam et al., Out of 198 cases, preoperative clinical diagnosis correlated with final histopathology reports in 195 cases (98\%). ${ }^{11}$ In three cases, the preoperative clinical diagnosis and postoperative diagnosis were different. In our study, the corresponding figure is $95 \%$ and in $5 \%$ of the cases, there was no correlation -cases of adenomyosis, premalignant lesions of cervix etc.

During the follow-up period a considerable number of women, especially those who had oophorectomy in the pre and perimenopausal period came with complaints of backache/hot flushes/loss of libido and mild depression. These women were counselled and given the required treatment-local and systemic estrogen and calcium etc.

\section{CONCLUSION}

Hysterectomy is one of the commonest surgical procedure done for many gynaecological problems. A considerable number of hysterectomies can be reduced by adequate counselling of the women and also by medical /conservative surgical treatments. Hysterectomies were decided in those situations where the above measures fail and also where it was found to be the definitive management in the first instance. Woman's option has also to be considered in certain cases. The route of hysterectomy has to be decided on case to case basis and choice of the attending clinician. Oophorectomy in the premenopausal women has to be decided depending on the condition of the ovaries witnessed at the time of surgery\& also the severity of symptom complex.

\section{Funding: No funding sources}

Conflict of interest: None declared

Ethical approval: The study was approved by the Institutional Ethics Committee

\section{REFERENCES}

1. Rees M. Menstrual Problems: menorrhagia and primary dysmenorrhea. In Dewhurst's textbook of obstetrics and gynaecology. Ed Keith Edmond $7^{\text {th }}$ ed. Blackwell publishers' pp 399-406.

2. Neela M, Mayonda IT. The hysterectomy story in the UK. J Midlife Health. 2013;4(1):40-1.

3. 2011 Women's Health Stats and Facts: The American Congress of Obstetricians and Gynaecologists 2011. Retrieved on June 23, 2015 Available at http://www.acog.org//media/NewsRoom/ mediakit.pdf.

4. Yakasai IA. Complications of Hysterectomy: A review. British J Sci. 2013;9(2):78-87.

5. Shridevi AS, Madhusoodana RB, Gayatri L Patil, Renuka. An analysis of elective hysterectomies at a tertiary care center in Karnataka. Int J Clin Obstet Gynaecol 2019;3(4):68-70.

6. John CO, Alegbeleye JO, Otoide AO. Foetomaternal outcome of diabetes in a tertiary health facility in Nigeria. African J Diabetes Med. 2015;23(2). 
7. Amirikia H, Evans TN. Ten-year review of hysterectomies: trends, indications, and risks. Am J Obstet Gynecol. 1979;134(4):431-7.

8. Rao PMR. To Study the Trends in Hysterectomy in A Tertiary Care Hospital Based On The Indications of Hysterectomy. IOSR J Dental and Medic Sci. 2019;18(4):49-53.

9. Patil HA, Mahajan SV, Patil A. Histopathological findings in uterus and cervix of hysterectomy specimens. MVP J M Sci. 2015;2(1):26-9.

10. American College of Obstetricians and Gynecologists. ACOG Practice Bulletin No. 89. Elective and risk reducing salpingo-oophorectomy. Obstet Gynecol. 2008;111:231-41.

11. Sivapragasam V, Patil AB, Rengaswamy CK. "An audit of hysterectomies: indications, clinic pathological analysis of hysterectomy specimens, complications, in a tertiary care centre". IJRCOG. 2018;7:689-94.

12. Pandey D, Sehgal K, Saxena A, Hebbar S, Nambiar J, Bhat RG. An audit of indications, complications, and justification of hysterectomies at a teaching hospital in India. Int J Reprodu Med. 2014:2;2014.

13. Sait K, Alkhattabi M, Boker A, Alhashemi J. Hysterectomy for benign conditions in a university hospital in Saudi Arabia. Anna Saudi Med. 2008;28(4):282-6.

Cite this article as: Hymavathi $\mathrm{K}$, Madhuri PVS, Brahmini M, Madhubala S. Hysterectomy for benign conditions in a tertiary care centre: a clinical audit. Int J Reprod Contracept Obstet Gynecol 2021;10:975-81. 